\title{
CARACTERIZAÇÃO MICROESTRUTURAL DO REVESTIMENTO DISSIMILAR DE AÇO INOXIDÁVEL AUSTENÍTICO AISI 316L, SOBRE A FACE DE UMA SOLDA DO AÇO CARBONO ASTM A516 GRAU 70*
}

\author{
Hélio PiresJunior ${ }^{1}$ \\ Sérgio Neves Monteiro ${ }^{2}$ \\ Verônica Scarpini Candido ${ }^{3}$ \\ Alisson Clay Rios da Silva ${ }^{4}$
}

\section{Resumo}

A compreensão do comportamento de materiais soldados é de extrema importância para a produção de materiais resistentes mecanicamente e, também, à corrosão. Nesse contexto, esse trabalho tem por objetivo caracterizar metalurgicamente a microestrutura resultante do aço inoxidável usado como revestimento dissimilar em soldagem de chapas de aço carbono. Utilizaram-se duas chapas de aço carbono como metal base e o revestimento dissimilar de aço inoxidável no cordão de solda. O processo de soldagem utilizado foi o de Arco Submerso (SAW) e realizaram-se os ensaios de tração e dureza, além de observação da microestrutura por microscopia ótica. Os resultados obtidos indicaram que o revestimento dissimilar no cordão de solda proporcionou valores elevados de residência à tração. Além disso, os valores de dureza sugerem que o material estudado pode ser aplicado em ambientes de caráter corrosivo.

Palavras-chave: Aço carbono; Aço Inoxidável; Revestimento; Soldagem.

\section{MICROSTRUCTURAL CHARACTERIZATION OF AISI 316L AUSTENITIC STAINLESS STEEL DISSIMILAR COATING ON THE FACE OF AN ASTM A516 GRADE 70 CARBON STEEL WELD.}

\begin{abstract}
The aim of this work is characterize metallurgically a microstructure resulting from stainless steel used as a dissimilar coating on welding of carbon steel sheets. Two carbon steel plates were used as the metal base and the dissimilar stainless steel coating on the weld bead. The sale process used for the Submerged Arc (SAW) and the tests carried out for the tensile strength and Vickers hardness, besides observation of the microstructure by optical microscopy. The results indicated that the dissimilar coating no weld bead provided high values of tensile strength. In addition, the hardness values suggest that the studied material can be applied in corrosive environments.
\end{abstract}

Keywords: Carbon Steel; Coating; Stainless Steel; Welding.

1 Engenheiro Mecânico/ Engenharia Mecânica, Mestre, Aluno de pós-graduação, Centro Universitário da Zona Oeste (UEZO), Rio de Janeiro - Rio de Janeiro, Brasil.

2 Engenheiro de Materiais/Engenharia de Materiais, PhD, Professor, Programa de Pós-graduação em Engenharia de Materiais/Departamento de Engenharia mecânica e Materiais, Instituto Militar de Engenharia (IME), Rio de Janeiro, Rio de Janeiro, Brasil.

3 Bióloga/ Ciências Biológicas, Doutora, Professora Adjunta I, Faculdade de Engenharia de Materiais, Universidade Federal do Pará, Ananindeua- PA, Brasil.

4 Químico industrial/ Química Industrial, Doutor, Professor Adjunto I, Faculdade de Engenharia de Materiais, Universidade Federal do Pará, Ananindeua, Pará, Brasil. 


\section{INTRODUÇÃO}

Um grande número de materiais metálicos pode ser empregado na fabricação de equipamentos e tubulações industriais, e entre todos esses metais, o aço carbono é o que tem maior uso sendo empregado na construção da grande maioria de equipamentos como vasos de pressão [1].

Os aços carbono são conhecidos como aços de uso geral, já que podem ser usados em diversas aplicações, no entanto apresenta limitações técnicas, principalmente no que diz respeito a trabalho em baixas temperaturas e em meios corrosivos. Os aços-liga e os aços inoxidáveis apresentam propriedades não encontradas nos aços carbono, porém representam um custo muito maior em relação a este aço, tanto em sua produção, quanto na montagem e soldagem em instalações industriais [2].

Quando o aço carbono não resiste à corrosão ou erosão, ou quando este material pode ainda causar contaminação ao produto, são utilizadas outras ligas ou revestimentos de materiais mais resistentes, metálicos ou não metálicos, que são aplicados sobre o aço carbono a fim de diminuir custos, como os aços inoxidáveis [3].

Os aços inoxidáveis são classificados conforme sua microestrutura predominante, e podem ser austeníticos, ferríticos e martensíticos. Por serem facilmente soldáveis, os aços inoxidáveis austeníticos são usados para construção e revestimento anticorrosivo de equipamentos e tubulações. Para os outros aços inoxidáveis, não é recomendável seu uso como aço estrutural ou soldados, exceto para alguns aços ferríticos de teor de cromo até $17 \%$, que apresentam soldabilidade não tão ruim, e têm um coeficiente de dilatação próximo ao do aço carbono [4].

A vantagem dos materiais metálicos revestidos é que o produto final combina as propriedades superiores de cada metal - resistência, resistência à corrosão, baixo peso, menor custo e condutividade térmica e elétrica - para produzir um material superior a qualquer um dos dois metais individualmente [5].

Os processos de revestimentos metálicos mais comuns são a cladização, onde os clads constituem-se de chapas de um metal ou ligas, resistentes à corrosão, revestindo e protegendo outro metal com função estrutural e podem ser aplicadas por pressão, laminação, solda ou explosão [6].

A seleção do processo de soldagem para revestimento é tão importante quanto a seleção da liga. Os requerimentos de desempenho em serviço não são ditados somente pela seleção da liga, mas sofrem forte influência de um processo de soldagem bem selecionado. Outros fatores técnicos envolvem a seleção do processo, incluindo as propriedades e a qualidade do revestimento, as características físicas da peça, as propriedades metalúrgicas do metal de base, a forma e composição da liga de revestimento e a habilidade do soldador [7].

Uma das variáveis mais importantes que devem ser observadas no caso da soldagem de revestimento de aços carbono com aços inoxidáveis é o controle do percentual de diluição. As taxas de diluição devem ser controladas e ajustadas para garantir a qualidade final do revestimento, como a manutenção das propriedades mecânicas e de resistência à corrosão, além da geometria adequada do cordão de solda $[7,8]$.

Um dos principais problemas metalúrgicos encontrados em soldas de metais dissimilares é a formação, ao longo da interface da linha de fusão, de regiões que podem atingir durezas superiores a $400 \mathrm{HV}$, o que indicaria presença de martensita e, portanto, de características frágeis da microestrutura [9]. Como forma de 
prevenção alguns estudos sugerem que o material deve ser pré-aquecido a uma temperatura maior ou igual a $2^{\circ} \mathrm{C}[8,10]$. Dessa forma, esse trabalho tem por objetivo avaliar as propriedades mecânicas e microestruturais do revestimento dissimilar de Aço inoxidável AISI 316L, sobre a face de uma solda do aço carbono ASTM A516 Gr. 70.

\section{MATERIAIS E MÉTODOS}

Neste trabalho foram utilizadas duas amostras de chapa de aço carbono ASTM A 516-06-70 [11] de $25 \mathrm{~mm}$ de espessura, cortadas com dimensões de 200 $\mathrm{mm}$ de largura e $500 \mathrm{~mm}$ de comprimento cada, que posteriormente foram unidas por solda de topo. A posição de soldagem foi a plana $1 \mathrm{G}$, seguindo as diretrizes da norma ASME IX [2]. A tabela 1 apresenta a composição química do aço.

Tabela 1. Composição química do aço carbono ASTM A 516-06-70

\begin{tabular}{cccccccccccccccccc}
\hline Elemento & $\mathrm{C}$ & $\mathrm{Si}$ & $\mathrm{Mn}$ & $\mathrm{P}$ & $\mathrm{S}$ & $\mathrm{Al}$ & $\mathrm{Cu}$ & $\mathrm{Ni}$ & $\mathrm{V}$ & $\mathrm{Ti}$ & $\mathrm{Cr}$ & $\mathrm{Ni}$ & $\mathrm{Sn}$ & $\mathrm{N}$ & $\mathrm{As}$ & $\mathrm{Outros}^{*}$ \\
\hline $\begin{array}{c}\text { \% em } \\
\text { peso }\end{array}$ & 0,22 & 0,18 & 0,99 & 0,018 & 0,008 & 0,039 & 0,02 & 0,08 & 0,002 & 0,03 & 0,03 & 0,02 & 0,002 & 0,0055 & 0,002 & 0,0005 \\
& & & & & & & & & & & & & & & & &
\end{tabular}

\section{${ }^{*}$ valores traço.}

A soldagem para união das chapas foi realizada a arco submerso (SAW) sendo que o cordão de solda recebeu uma camada de revestimento em aço inoxidável AISI 316L, depositada por processo de eletroescória.

Após a etapa de soldagem, foram realizados os ensaios de tração e dureza. O ensaio de tração foi realizado de acordo com a norma ASTM-A 370 [12] e os corpos de prova foram ensaiados em máquina de ensaio hidráulica universal, de faixa nominal $100 \mathrm{Mp}$ da VEB-WPM, modelo 1974, com escala de 0 a 40 Ton. A dureza analisada foi a Vickers, seguindo as diretrizes na norma ASTM E 92 [13]. Para medição de dureza na seção transversal, o corpo de prova foi confeccionado de acordo com a norma ASTM E 340 [14]. Os testes ocorreram à temperatura ambiente, usando uma carga de 10,0 Kgf, com tempo de carregamento de 10 a 15 segundos. Foi utilizado como referência para avaliação a norma PETROBRAS N133 Revisão J [16] e o valor requerido foi de $\leq 248$ HV.

As amostras destinadas a análise metalográfica foram, inicialmente, cortadas, lixadas e limpas com álcool etílico. Posteriormente, foram polidas com pasta de diamante de 3, 2,5 e $1 \mu \mathrm{m}$ e utilizou-se álcool etílico como lubrificante. Utilizou-se o Murakami como reagente a fim de revelar e colorir a superfície tornando possível a observação da microestrutura que foi realizada em microscópio ótico da Zeiss.

\section{RESULTADOS E DISCUSSÃO}

A tabela 2 apresenta os resultados obtidos por tração nos corpos de prova. 
Tabela 2. Ensaio de tração nos copos de prova soldados

\begin{tabular}{|c|c|c|c|c|c|c|c|}
\hline $\begin{array}{c}\text { Corpo } \\
\text { de prova }\end{array}$ & $\begin{array}{c}\text { Largura } \\
(\mathrm{mm})\end{array}$ & $\begin{array}{c}\text { Espessura } \\
(\mathrm{mm})\end{array}$ & $\begin{array}{c}\text { Área } \\
\left(\mathrm{mm}^{2}\right)\end{array}$ & $\begin{array}{c}\text { Carga } \\
\text { Máxima } \\
\text { (Kgf) }\end{array}$ & $\begin{array}{c}\text { Limite de } \\
\text { resistência à } \\
\text { tração } \\
\left(\mathrm{Kgg} / \mathrm{mm}^{2}\right) \\
(49,45 \mathrm{Min})\end{array}$ & Fratura & Local \\
\hline 1 & 18,70 & 25,10 & 469,37 & 28.000 & 59,65 & Dúctil & $\begin{array}{c}\text { Cordão } \\
\text { de } \\
\text { solda }\end{array}$ \\
\hline 2 & 18,70 & 25,10 & 741,88 & 28.400 & 60,18 & Dúctil & $\begin{array}{c}\text { Cordão } \\
\text { de } \\
\text { solda }\end{array}$ \\
\hline
\end{tabular}

Os valores de limite de resistência à tração para o aço SA-516-70 encontrados nesse estudo são similares e, estão acima dos valores mínimos exigidos pela ASME que é de $49,45 \mathrm{Kgf} / \mathrm{mm}^{2}$. Além disso, os ensaios mostraram que a fratura nos corpos de prova apresentou aspecto dúctil e ocorreu no cordão de solda.

A manutenção dos limites de resistência com valores acima do limite mínimo necessário indica que houve pouca ou nenhuma influência da diluição entre o revestimento e o metal de adição em aço carbono.

Segundo SMITH (2012) [16] dependendo da composição exata dos materiais unidos, uma gama de microestruturas pode ser formada na zona diluída e pode existir um potencial para formar uma fase martensítica, cuja dureza pode ser definida pelo teor de carbono fundido a partir do metal de base. A martensita está relacionada à alta dureza, mas ao mesmo tempo à fragilidade do material. Valores muito próximos ou abaixo do limite de resistência mínimo poderiam indicar presença desta fase.

Ainda segundo SMITH (2012) [16], do ponto de vista mecânico para aplicações a temperatura ambiente, a zona de interface entre os metais dissimilares não apresenta uma grande preocupação. A resistência à tração é elevada, e por isso não são comuns falhas nesta região.

Os resultados dos ensaios de dureza Vickers estão apresentados na tabela 3.

\begin{tabular}{ccccc}
\multicolumn{5}{c}{ Tabela 3. Valores de Dureza Vickers } \\
\hline Região & Ponto & $\begin{array}{c}\text { Dureza } \\
\text { (HV) }\end{array}$ & Ponto & $\begin{array}{c}\text { Dureza } \\
\text { (HV) }\end{array}$ \\
\hline Material de & 1 & 192 & 12 & 206 \\
Base & 2 & 219 & 13 & 208 \\
& 3 & 219 & 14 & 203 \\
& 4 & 212 & 15 & 208 \\
\hline Material de & 5 & 185 & & \\
Solda & 6 & 175 & 16 & 201 \\
& 7 & 187 & & \\
\hline ZAC & 8 & 191 & 17 & 208 \\
& 9 & 199 & 18 & 212 \\
\hline Material de & 10 & 212 & 19 & 199 \\
Base & 11 & 190 & 20 & 204 \\
\hline
\end{tabular}

Nota-se que os valores de dureza Vickers obtidos ficaram abaixo de $248 \mathrm{HV}$, mínimo exigido pela norma NACE MR0175 [17]. De acordo com essa norma, valores de dureza Vickers acima de 248HV indica que o aço é suscetível a corrosão sob 
tensão. Os valores encontrados nesse estudo, por estarem abaixo do valor indicado, sugerem que esse aço carbono revestido com aço inoxidável AISI 316L pode ser utilizado em ambientes de caráter corrosivo como os ambientes ácidos.

A figura 1 representa a variação dos valores de dureza encontrados ao longo da seção transversal.

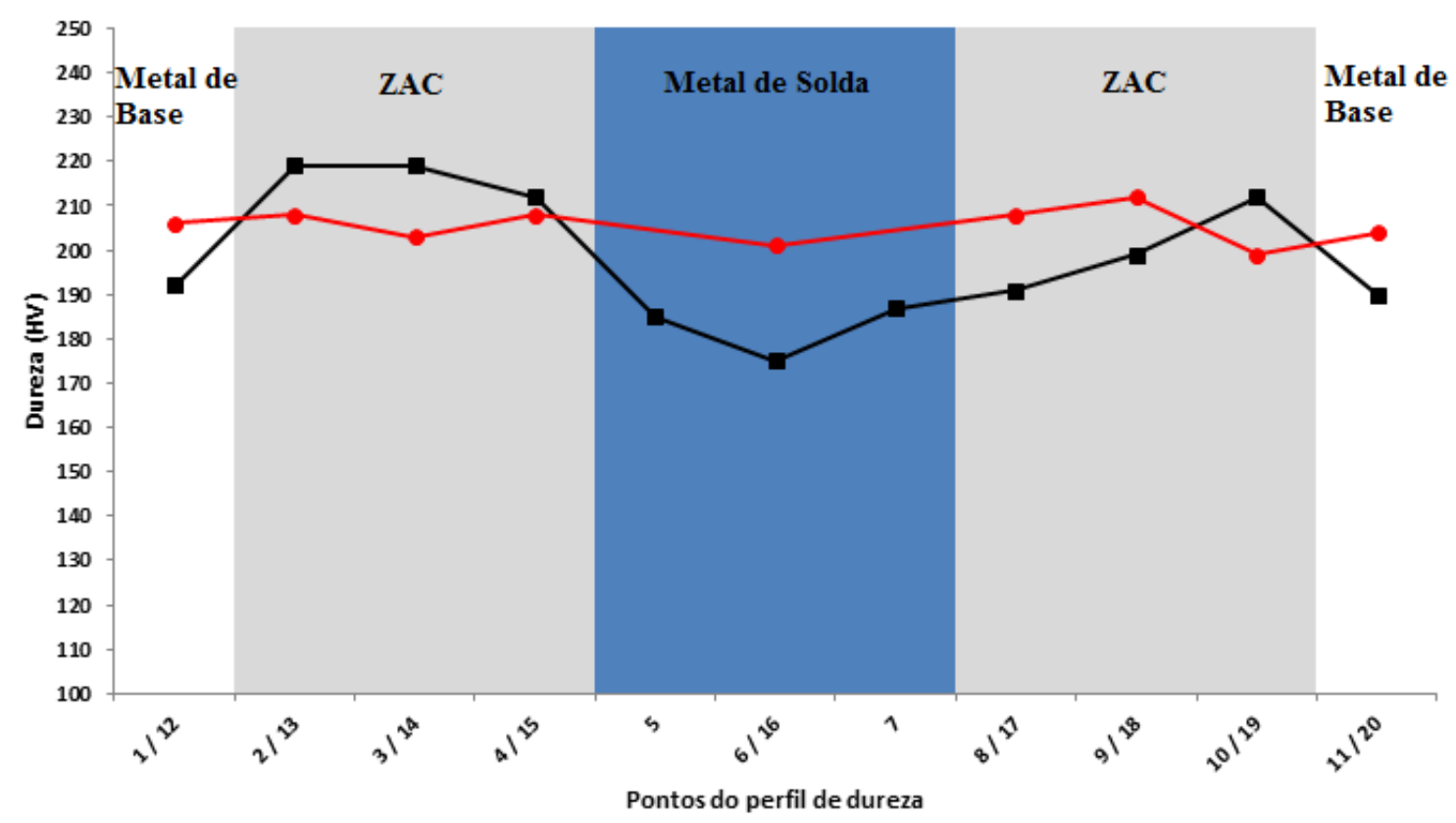

$\rightarrow$-DURE ZA(HV) FACE SUPERIOR $\quad \rightarrow$-DURE ZA (HV) FACE INFE RIOR

Figura 1. Valores de dureza Vickers por zona do corpo de prova.

É possível verificar que os maiores valores de dureza encontram-se na Zona Afetada pelo Calor (ZAC), principalmente próximos à face superior, onde a poça de fusão formada é maior, além de também ter recebido revestimento sobre o cordão de solda. Nas proximidades de ambas as faces, os valores mais baixos foram encontrados no centro do metal de solda, e para o metal de base, os valores encontrados próximos à face inferior são maiores que os da face superior.

A ZAC é a região que se caracteriza por apresentar um ciclo térmico de rápido aquecimento, seguindo de rápido resfriamento, causado pela fonte de energia utilizada na soldagem e por dissipação através da ZAC, respectivamente. Por esta razão o material sofre transformações metalúrgicas complexas, bem como a indução de deformações e tensões residuais.

Ainda que abaixo do valor de referência utilizado para dureza Vickers, os níveis de dureza mais elevados, encontrados na ZAC, podem ser justificados, segundo MODENESI (2012) [18], pelo aumento da temperabilidade da região de granulação grosseira (devido ao aumento do tamanho de grão austenítico). Essa região é caracterizada por uma microestrutura rica em constituintes aciculares como bainita e martensita. Assim, tende a ser a região mais problemática da ZAC, podendo apresentar dureza elevada, perda de tenacidade e ser um local comum para a formação de trincas. Esses problemas são comuns para aços com teor de carbono mais elevado (maior temperabilidade e elevadas dureza e fragilidade da martensita) e para aços ligados (maior temperabilidade).

A figura 2 apresenta a micrografia obtida por microscopia ótica do material de revestimento sobre o cordão de solda. 


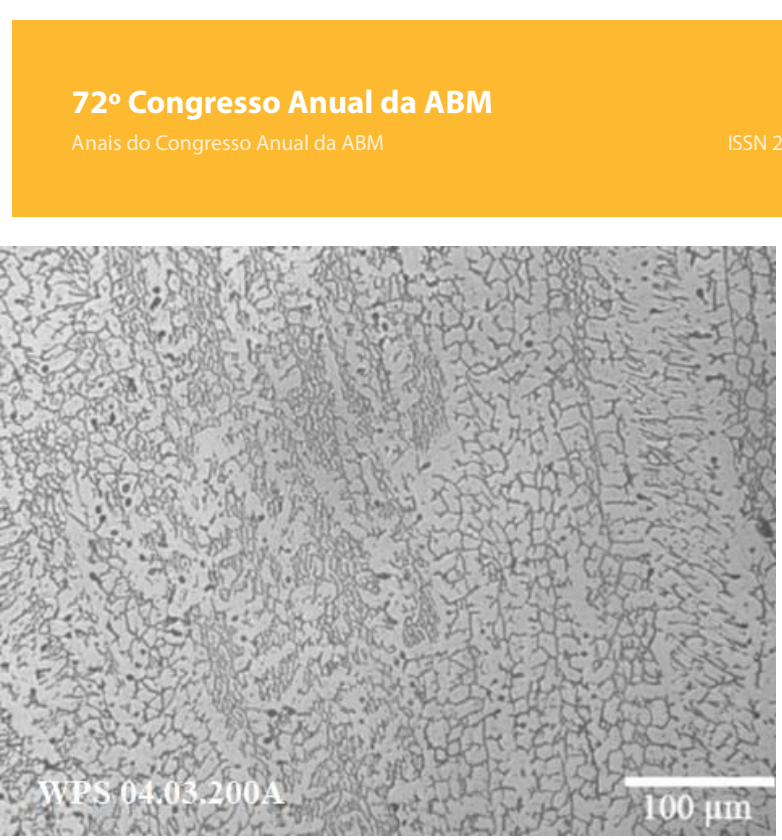

(a)

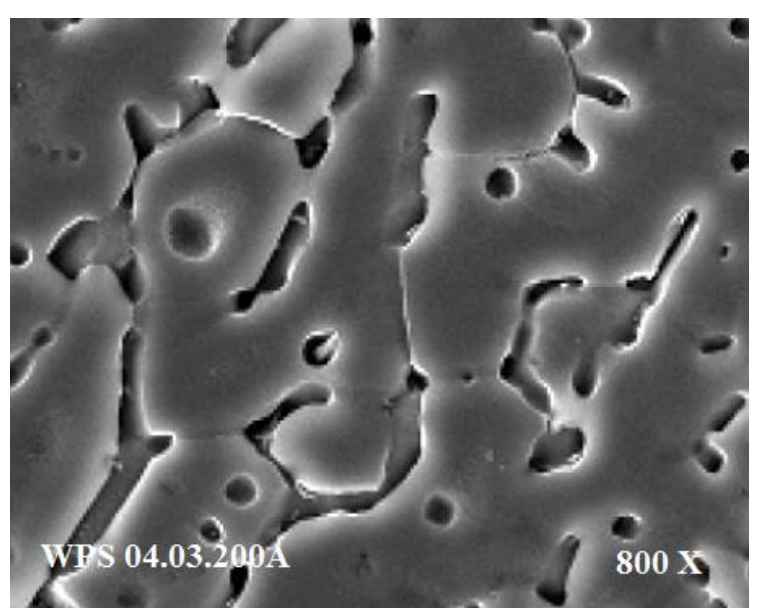

(b)

Figura 2. Micrografia obtida por microscopia ótica. (a) Zona fundida do aço inox AISI 316L, aumento de 800x e (b) Zona fundida do aço inox AISI 316L mostrando a formação da ferrita delta, aumento de $800 x$.

As micrografias e revelaram uma microestrutura de matriz austenítica e de ferrita delta nos espaços interdendríticos. Além disso, as micrografias mostraram que a zona fundida do material de revestimento apresenta uma estrutura que consiste de ferrita delta com diferentes morfologias em uma matriz de austenita. As morfologias da ferrita delta formam regiões de ferrita acicular, vermicular e ferrita de contorno de grão (Fig. 2 (a)).

A ferrita delta distribuída na matriz austenítica apresenta morfologias distintas de acordo com sua formação durante a taxa de resfriamento após o processo de solda $[18,19]$.

Observa-se ainda, na Fig. 2 (b) uma matriz austenítica e a fase dispersa de cor escura, encontrada com diferentes morfologias, que corresponde à ferrita delta formada na zona fundida após soldagem.

A ferrita delta é benéfica aos aços inoxidáveis austeníticos, minimizando o efeito da dissolução do cromo e prevenindo a corrosão intergranular tão indesejada nesse tipo de aço.

Dessa forma, o estudo sobre as características mecânicas e microestruturais do aço carbono ASTM A516 Gr 70 revestido com aço AISI 316L soldado pelo processo SAW revelou que o processo de soldagem não influenciou negativamente na resistência à tração tão pouco na dureza do metal base, indicando que o processo de soldagem por eletroescória pode ser aplicado em diversos setores industriais, como o de fabricação de vasos sob pressão.

\section{CONCLUSÃo}

A análise das características mecânicas e microestruturais do revestimento dissimilar de Aço inoxidável AISI 316L, sobre a face de uma solda do aço carbono ASTM A516 Gr. 70 soldado pelo processo SAW revelou:

- A aplicação de revestimentos metálicos de materiais dissimilares sobre metais de base em aço carbono pelo processo de soldagem eletroescória demonstra ser vantajosa, não só pelo menor custo e alta produtividade, mas também pela sua característica de proporcionar baixas taxas de diluição, sem prejuízo das propriedades metalúrgicas. 
- O ensaio de tração demonstrou que as propriedades de resistência mecânica foram mantidas, mesmo com a adição de material dissimilar ao metal de base.

- Os resultados para o ensaio de dureza Vickers apresentaram valores de medição ao longo da seção transversal abaixo das que poderiam indicar presença de martensita.

\section{REFERÊNCIAS}

1 Balasubramanian, V, Lakshminarayanan, AK, Varahamoorthy, RE, Babu, S. Application of response surface methodology to prediction of dilution in plasma transferred arc hardfacing of stainless steel on carbon steel. International Journal of Iron and Steel Research, 2009. v. 16, n. 1, p. 44-53.

2 Aws. Welding Handbook: Welding Processes. American Welding Society, v. 2. 8th ed. Miami, 955 p., 1992.

3 Brandi, SD, Liu, S, Thomas Jr., RD, Welding, Brazing and Soldering. Electroslag and Electrogas Welding*, ASM Handbook, ASM International, 2008, 15:124-138.

4 Butt, MTZ.; Ahmad MS.; Azhar, M.; characterization for GTAW AISI 316 to AISI 316 \& SA 516 grade 70 steels with welded \& prewelded annealing conditions, Journal of Quality and Technology Management, 2012, 8(2): 119_ 133.

5 Shahi, AS, Pandey, S. Modelling of the effects of welding conditions on diluition of stailess steel claddings produced by gas metal arc welding procedures. Journal of Materials Processing Technology, 2008. 196(1): 339344, 2008.

6 Smith, L. Engineering with CLAD STEEL. 2nd Edition, Nickel Institute Technical Series No 10 064, October, 2012.

7 Telles, PCS. Vasos de pressão. 2ª . Edição, Editora LTC, 1996.

8 Rao, V, Rao, NBR, Mohan RK. "Disbonding Studies of Austenitic Stainless Steel Weld Overlays on 2,25 Cr-1 Mo Steels. 2012, Issue 2, Vol.5.

9 American Society For Metals - Stainless Steel Cladding and Weld Overlays. ASM Specialty Handbook: Stainless Steels, 06398G, 1994

10 Palani, PK.; Murugan, N., Karthikeyan, B. Process parameter selection for optimising weld bead geometry in stainless steel cladding using Taguchi's approach. Materials Science and Technology, 2006, 22(10): 1193-1200. 
11 American Society of Testing and Materials. ASTM A 516/A 516 M - Standard specification for pressure vessel plates, carbon steel, for moderate and lower temperature services. ASTM A 526/516M - 90 (Reapproved 1996);

12 American Society of Testing and Materials. ASTM A 370 -17. Standard Test Methods and Definitions for Mechanical Tensting of Steel Products. 2017.

13 American Society of Testing and Materials. ASTM E - 92. Standard Test Methods for Vickers Hardness and Knoop Hardness of Metallic Materials. 2016.

14 American Society of Testing and Materials. ASTM E 340. Standard Practice for Macroetching Metals and Alloys. 2015.

15 Petrobrás N - 133. Soldagem. Revisão J. Jun. 2005.

16 Smith, L. Engineering with CLAD STEEL. 2nd Edition, Nickel Institute Technical Series No 10 064, October, 2012.

17 Nace MR0175. Materiais para uso em ambientes com H2S e produção de óleo e gás na indústria de Petróleo e Gás. 2015.

18 Modenesi, PJ. Soldabilidade dos Aços Inoxidáveis. Senai, Osasco- SP, 2001

19 Ferriere, A, Bautista, CS, Rodriguez, GP, Vazquez, AJ. Corrosion resistance of stainless steel coatings elaborated by solar cladding process. Solar Energy, 2006, 80(10): 1338-1343. 